\title{
Construction and Strategy Analysis on the Talent Cultivation Program of New-Type Application-Oriented Undergraduate Colleges
}

\author{
Zhu Qiu, Xi Zhang, Genhua Zhang* \\ Changshu Institute of Technology, Changshu, Jiangsu 215500, China \\ "Corresponding author.Email: qiuzhu@cslg.edu.cn (Zhu Qiu), zgh@cslg.edu.cn (Genhua Zhang)
}

\begin{abstract}
New-type application-oriented undergraduate colleges are an important part of China's higher education landscape. The top-level design of the overall optimization of the talent cultivation program is an important link for the colleges to form characteristics, enhance core competitiveness, and promote the connotation construction of teaching. This paper defines the connotations and features of the new-type application-oriented undergraduate colleges, and points out the strategic principles of the talent cultivation program, and illustrates their main construction elements and characteristics. It provides a reference for constructing a scientific and reasonable talent training program.
\end{abstract}

Keywords: application-oriented undergraduate colleges, talent cultivation program, construction

\section{INTRODUCTION}

New-type application-oriented undergraduate colleges mainly refer to the "application-oriented newly established undergraduate colleges", that have been upgraded since 1999 and have the fundamental purpose of cultivating applied talents needed for serving local economic and social development [1-3]. The development of such colleges and universities has been caught in the development dilemma due to the limitations of China's higher education system, such as a single evaluation system, a unified funding method, and the failure to implement college autonomy. In order to expand the development space of the school and give full play to the higher education functions of colleges in personnel cultivation, scientific research, social services, cultural inheritance and innovation, new-type applicationoriented undergraduate colleges choose to seize the opportunities for the development of a new round of transformation and development under the background of economic transformation and upgrading and social development, structural adjustment of higher education, and strengthened connotation construction [2,4-5].

How to find out their own development space in the development of society and higher education, form school running characteristics, enhance core competitiveness, and improve the quality of talent cultivation? The overall optimization of the top-level design of the applied talent cultivation program based on high calibration positioning and serving local and social development plays a vital role. In recent years, Changshu Institute of Technology has conducted useful explorations on this.

\section{CHARACTERISTICS OF APPLICATION-ORIENTED UNDERGRADUATE TALENT CULTIVATION MODEL}

The application-oriented undergraduate talent cultivation model refers to the goal of applying-oriented undergraduate talent cultivation, combining general education and professional education, building the subject based on demand, and building a curriculum system based on subject and application-oriented. The combination of production, education and research is the main cultivation approach, and the evaluation of teaching is based on ability. The teaching team pays attention to the combination of theory and practice [6-7]. Its characteristics are as follows:

\subsection{Demand Orientation}

Construction of disciplines and specialties is based on demand: focusing on the development of applied disciplines; setting specialties according to social needs; adjusting professional directions according to social needs; establishing a demand-oriented professional setting and adjustment mechanism.

\subsection{Application Orientation}

Curriculum system development is application-oriented, taking professional application ability as the starting point of professional course design, transforming the characteristics of professional application ability into 


\subsection{Basis Utility and Appropriate Scope}

ability-based course system.

\subsection{Ability Orientation}

Ability-oriented evaluation is adopted, that evaluate students 'ability to apply knowledge and solve practical problems. At the same time, establishing a teaching evaluation method of ability orientation must pay more attention to the evaluation of students' social adaptability and self-development ability.

The above characteristics are the manifestation of the talent cultivation model of the new-type application-oriented undergraduate colleges, which is different from the academic research universities and the vocational skill colleges (vocational colleges). More emphasis is placed on basic application and strengthening practice integration [2], general education and personalized cultivation integration, diversified cultivation and whole-person education integration.

\section{STRATEGIC PRINCIPLES OF APPLICATION-ORIENTED UNDERGRADUATE TALENT CULTIVATION PROGRAM}

Compared with academic talents, applied undergraduate talents are mainly engaged in non-academic research work under the guidance of certain theoretical norms. Their task is to convert abstract theoretical symbols into specific operational concepts or product configurations. Knowledge is applied in practice [8]. In view of the characteristics of application-oriented talents in new-type applicationoriented undergraduate colleges, the following principles were followed when formulating talent cultivation program.

\subsection{Ability Basis and Overall Optimization}

On the basis of fully understanding the market, closely combining the job capacity requirements and professional characteristics, comprehensively introducing expert suggestions from engineering education, industry, and social management departments, redefining the cultivation goals and graduation requirements of each major for easy evaluation. According to the position general ability and professional ability matrix, determine the structure of each professional curriculum system, clarify the logical relationship of the curriculum, and reverse design the curriculum system and curriculum teaching content. Establish a continuous improvement mechanism to further clarify the correspondence between cultivation goals, graduation requirements, teaching links and teaching content, and improve the consistency and execution of the four.
The development of application-oriented talent cultivation program should focus on job capabilities, with greater emphasis on the ability to integrate and apply knowledge, and fully embody the original talent cultivation concept of "practical foundation, appropriate scope, heavy application, strong ability". The application of general knowledge courses (focusing on the cultivation of students' basic literacy and general ability), the use of subject basic courses (emphasis on training students' professional basic knowledge and basic skills), and the use of professional courses (emphasis on training students' professional skills required for professional positions) should be achieved. Based on factors such as professional characteristics, market demand, students' adaptability and development stamina, the proportion of credits for various courses is reasonably determined. Students are further encouraged to choose courses across second class colleges and majors. In principle, each major must formulate a teaching plan for minor majors that can be taken by non-major students, giving students more choices for learning, encouraging students 'personality development, and promoting some compound talent development.

\subsection{Practice and Innovation}

It is important to construct practical teaching system with ability cultivation as the main line, and promote the reform and innovation of experimental content and experimental mode. Also, it is necessary to appropriately increase the proportion of practical teaching in the total credits of the talent cultivation program, attach importance to teaching practice, and vigorously promote the "dual tutor system" of student graduation design (thesis), appropriately add practical cultivation links, increase practical training, and improve students' practical ability and employability.

These measures are considered to be effective in improving students' practical and innovative abilities, such as vigorously promoting the implementation of quality expansion credits, actively participating in scientific research or in relevant subject competitions, writing academic papers, obtaining corresponding credits while in college through cultural or sports competitions. In order to improve the level of experimental courses, it is necessary to promote integrating multiple theoretical courses to create designed, comprehensive and innovative experimental project, especially to encourage the establishment of experimental-oriented learning courses (based on projects, cases, problems, etc.), to promote "doing by studying", "learning by doing", "thinking by doing" and many other practical teaching methods effectively improve students' practical and innovative ability. 
cultivation of field engineers with international vision, innovative spirit and practical ability.

Professional-level cultivation goals require a deeper interpretation of the connotation of college cultivation goals The cultivation objectives at the professional level should be based on the characteristics of the profession, society, and industry, and emphasize the students' requirements in terms of knowledge, ability, and quality, as well as the occupations they are engaged in, and clarify the employment field and nature of the graduates of this major and the social competitiveness. should have the consciousness of actively serving the needs of industry enterprises. On the basis of making the "Industry College" practical and strong, it is important to further innovate the new mechanism of joint cultivation of talents with industry enterprises by taking students as the center, career as the guidance, and ability as the basis. It is an effective way for improving students 'engineering practice innovation ability and enhancing students' employment competitiveness through the joint development of cultivation standards, joint design of cultivation objectives, joint development of cultivation program and joint implementation of the cultivation process by colleges and enterprises.

\section{CONSTRUCTION ELEMENTS OF APPLICATION-ORIENTED UNDERGRADUATE TALENT CULTIVATION PROGRAM}

Talent cultivation program is the top-level design and implementation blueprint for talent cultivation in colleges and universities, which reflects the organization of teaching process and the allocation of teaching resources. The foundation of the construction of the cultivation plan is to sort and decompose the "cultivation goal-graduation requirements (basic specifications)-course system" according to the engineering professional certification logic system.

\subsection{Talent Cultivation Goals}

The core factor in the talent cultivation program is the talent cultivation goal. The whole process of formulating talent cultivation program is based on the goal of talent training. There are two dimensions of talent cultivation goals: the overall goals at the school level and the cultivation goals at the professional level.

The overall goal positioning at the school level should comprehensively reflect the type, level, disciplines and service orientation of the colleges. Changshu Institute of Technology is a newly-built undergraduate college. Based on the college's positioning and development strategy, it puts forward the application-oriented talent cultivation concept of "focusing on general knowledge and integrating into the industry ", identifies the training objectives of highlevel applied technical talent mainly focusing on the

\subsection{Basic Specifications}

The basic specifications of the talent cultivation program include basic quality, knowledge structure, and ability structure, which are the decomposition and refinement of talent cultivation goals.

In terms of basic qualities, comprehensive qualities including good ideological and political qualities, humanistic qualities, professional qualities, physical and mental qualities, good social ethics and social responsibility are required.

In terms of knowledge structure, it should be "solid foundation, moderate scope". It is manifested in mastering the basic theories and basic knowledge of the subject, as well as the humanities and social science theories and methods that are suitable for the job, and at the same time, it must be able to carry out application-oriented and targeted research and practice in line with the needs of the industry [9].

In terms of capability structure, application-oriented talents are oriented to the industry, emphasizing the comprehensive application of scientific principles and technologies and the ability to solve practical problems, but also must have certain research, innovation, design, development or management, interpersonal communication and collaboration skills. More importantly, it is necessary to have the ability of sustainable development based on high comprehensive quality and subject knowledge system.

\subsection{Curriculum System}

\subsubsection{Course selection based on the cultivation of application talents}

Giving each secondary college and students sufficient "autonomy" can effectively increase the "flexibility" of the cultivation program and reduce the "rigidity", thereby enhancing the flexibility and suitability of the talent cultivation system and improving the flexibility of the talent cultivation system.

In the overall design of general and professional courses, the general courses are divided into fixed modules and dynamic modules. Each secondary college independently selects the dynamic module courses in the general courses 
according to the professional cultivation goals, reducing the required courses. The proportion of courses provides "space" for the optimization and adjustment of the overall talent cultivation program.

Increasing the credits of elective courses and the scope of elective courses can further increase the "flexibility" of talent cultivation program. Students are required to take elective courses in addition to public elective courses and professional elective courses, and can also choose supplementary professional courses or compulsory or elective courses of other majors according to their interests and hobbies. On this basis, students have sufficient "autonomy" in course selection. At the same time, make full use of the advantages of multi-disciplinary coordinated development to develop minor majors, encourage students to take the initiative to master cross-college, crossprofessional knowledge. The above-mentioned course selection framework provides students with various combinations of learning plates and collocations for the academic knowledge and abilities required to engage in certain occupations in a certain industry in the future. From the perspective of teaching management, the effective implementation of cross-specialty and cross-academic course selection is ensured.

\subsubsection{Optimized setting of course system based on learning effect}

The learning effect is a concrete manifestation of the goal of talent cultivation. Most of the implementation of talent cultivation programs are completed in various types of "courses". Therefore, it is necessary to correspond each type of "course" in the cultivation program with the final learning effect to ensure that the overall program promotes the process of talent cultivation target effectiveness delivery. The learning effect objectives are divided into four levels: (1) technical knowledge and reasoning; (2) personal abilities, professional abilities and attitudes; (3) interpersonal skills, including team work and communication; (4) in corporate and social environments conception, design, implementation, operation system [10]. The first level of technical knowledge and reasoning ability depends on the specific requirements of the profession, and the second, third and fourth levels are universal.

Based on the college's effectiveness of the curriculum system optimization, the main path includes integration, reorganization, optimization of the new curriculum system and teaching content, focusing on the locality, practice, flexibility and comprehensiveness of the curriculum, highlighting the relevance of the curriculum, strengthening the industry Practice and engineering training, paying attention to the formation and training of engineering ability, avoiding too detailed and narrow curriculum and unnecessary content repetition, tracking the evaluation of students' learning effect, understanding the knowledge, abilities and attitudes that students have when they graduate, and how well they master. Finally, a feedback mechanism is formed and a new round of cultivation program curriculum system is continuously improved.

\section{CONCLUSION}

Based on the characteristics of the application-oriented undergraduate talent model, combined with the social needs of the industry, the top-level architecture optimization design cultivation program is an important part of building an application-oriented talent cultivation system. How to highlight the application type, openness and locality in the actual process of talent cultivation, handle the relationship between theoretical teaching and practical teaching, general education and professional education, ability cultivation and knowledge transfer, subject logic and technical logic, etc. The corresponding relationship between the cultivation program, graduation requirements (graduation specifications), teaching links and teaching content, to improve the fit and execution of the four, also needs continuous improvement and continuous summary and improvement.

\section{ACKNOWLEDGMENT}

This work was supported by Educational Science "Thirteenth Five-Year Plan" Project of Jiangsu Province (D/2016/01/78)

\section{REFERENCES}

[1] Xiaohu, C., Xiang, Y. (2013) Fourteen basic problems in the development of new applicationoriented undergraduate colleges. China University Teaching, (1): 17-22.

[2] Xiaohu, C. (2014) Ten puzzles and reflections in the reform and development of new applied undergraduate colleges. China University Teaching, (7): 11-20.

[3] Xiaohu, C. (2014) Development orientation, mission, path and method selection of new applicationoriented undergraduate colleges. China University Teaching, (3): 33-40.

[4] Qiuheng, S. (2016) An empirical study on the national university classification system and its setting standards. Science Press, Beijing. pp. 195-200.

[5] Jingye, H. (2019) Thoughts and strategies on the new governance structure of applied undergraduate universities. Journal of Heilongjiang College of Education, 38(7): 4-6. 
[6] Maoyuan, P. (2011) Theory and practice of cultivation applied talents. Xiamen University Press, Xiamen. p. 63.

[7] Zubin, H., Su K. (2018) On the applied talent cultivation of new-type local undergraduate universities. Application-Oriented Higher Education Research, 3(2): 1-4, 10.

[8] Maoyuan, P., Huixia, S. (2009) Exploring the historical source of cultivation of applied talents. Jiangsu Higher Education, (1): 7-10.

[9] Zongfa, W. (2012) On applied undergraduate Talent's essential features and positioned specification. Higher Education Forum, (11): 3-5, 43.

[10] Peihua, G., Minfen, S., Xiaohua, L. (2009) Rethinking engineering education---- International CDIO cultivation model and method. Higher Education Press, Beijing. pp. 44-50. 